\title{
A PROCICLICIDADE DO SISTEMA BANCARIO EN ESPAÑA. ESTUDO DESCRITIVO DO COMPORTAMENTO DO NEGOCIO BANCARIO PERANTE O CAMBIO DE CICLO.
} Irene Clara PISÓNFERNÁNDEZ.

Dep. de Economía Financeira e Contabilidade. Universidade de Vigo, pison @uvigo.es Félix PUIME GUILLÉN

Depart. de Economía Financeira e Contabilidade. Universidade de Vigo, fiz @uvigo.es Miguel Ángel CRESPO CIBRÁN, Abanca. Máster en Finanzas. Facultade de CC. Económicas e Empresariais. Vigo.macrespo@yahoo.com

\begin{abstract}
Resumo: 0 estudo pretende analizar o grao de prociclicidade do negocio bancario e a relación entre os efectos da crise bancaria e a crise financeira. As conclusións extraídas da análise empírica do sistema bancario no período anterior e posterior ao comezo da crise confirman que o tratamento da xestión do risco bancario e do crédito deberá incluír non só a consideración de variables afectas ao debedor, senón todas aquelas vencelladas á economía en xeral.
\end{abstract}

Palabras chave: prociclicidade, crisis financieira, xestión do risco bancario JEL CODE: E44.

Title: The procyclicality of banking system in Spain . Descriptive study of the behavior of banking business before the cycle change .

Abstract: The purpose of this study is to analyze the degree of procyclicality of the banking business and the relationship between the effects of the banking crisis and the financial crisis. Conclusions extracted from the empirical analysis of the banking system in the periodsbefore and after the beginning of the crisis period confirm that the banking and credit risk management should take into consideration not only variables regarding the debtor, but all those related to the whole economy.

Key words: procyclicality, financial crisis, bank risk management.

\section{Introdución}

O obxectivo deste estudo é determinar como se comporta o conxunto das entidades bancarias en España en termos agregados, mediante a análise do negocio bancario, tentando comprobar tendencias e graos de dispersión, e os posibles cambios ao longo do tempo, interpretando a forma en que a evolución reflicte o episodio da crise económica e a súa tendencia, por tanto, á prociclicidade ${ }^{1}$.

Os datos son os relativos ás entidades bancarias sobre a base dos datos emitidos no Boletín Estatístico do Banco de España, de xuño de 2012 (cifras en millóns de euros).

1 A prociclicidade "consiste na amplificación das interaccións no seo do mesmo sistema financeiro e entre el e a macroeconomía”. (BPI. 2010, pg. 97). 


\section{Estudo empírico descritivo de magnitudes agregadas}

Neste apartado realízase un estudo empírico de carácter descritivo, a nivel agregado, do comportamiento das principais partidas do balance das entidades bancarias en España.

Na fase inicial tómase o período 2002-2011, para constatar o cambio de tendencia asociado á crise financeira e as consecuencias que isto implica sobre as variables máis representativas do estado das entidades bancarias.

Co fin de determinar os dous subperíodos, o anterior e o da crise, analízase como se comportan as variables referentes aos créditos e aos depósitos, compoñentes principais das entidades bancarias en España no período global considerado.

Obsérvase e interprétase o comportamento do negocio bancario, conxunto de créditos e depósitos, nos dous subperíodos obxecto de consideración (pre e post crise), realizando, en primeiro lugar, unha análise da evolución dos créditos e dos depósitos, a partir das taxas de crecemento e dos coeficientes de correlación, comparando os valores no período anterior e posterior á crise. En segundo lugar, abordarase un estudo das partidas de balance bancario agregado, tanto do activo como do pasivo, a fin de comprobar a transferencia entre as masas do balance ao longo do tempo e a variación nestes dous períodos.

\section{Análise da evolución dos créditos e dos depósitos}

A evolución dos créditos e dos depósitos formúlase a través das taxas de crecemento e dos coeficientes de correlación.

As taxas de crecemento calcúlanse como números índices, é dicir, tomando como base o valor inicial do período, analízase a porcentaxe de variación de cada observación con respecto ao mesmo. Os datos de créditos e depósitos para o cálculo das devanditas taxas achéganse na táboa 1 , e os correspondentes ás súas taxas de crecemento nese mesmo período, na táboa 2.

O gráfico adxunto representa as evolucións destas taxas.

Gráfico 1: Evolución das taxas de crecemento dos créditos e dos depósitos. Datos anuais para o período 2002- 2011. (Base: Táboa 2 Anexo táboas).

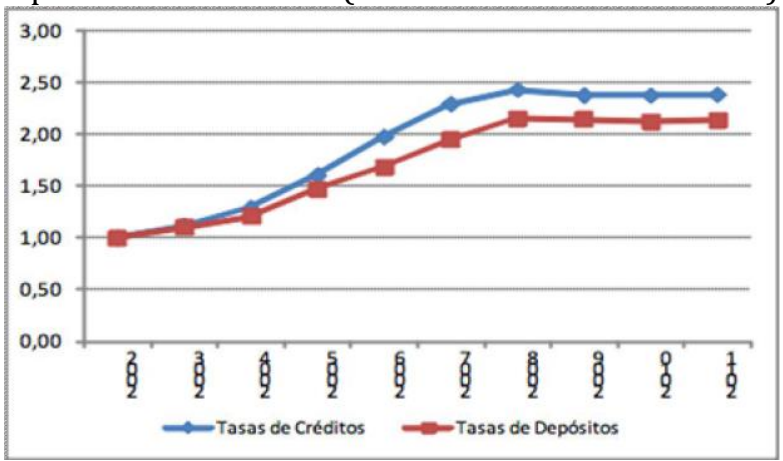

Da evolución das taxas de crecemento despréndese que: 
lz Os índices son crecentes dende o ano 2001 ata o ano 2008, tanto no que se refire ás dos créditos como dos depósitos, dado que son superiores á unidade, nos dous casos.

Taxa de variación créditos 2002/2008 $=2,43 / 1=2,43$.

Taxa de variación depósitos 2002/2008 = 2,15/1 = 2,15.

lz A partir do ano 2008 comezan a descender nas dúas variables, e son inferiores á unidade, en ámbolos casos, o que implica unha baixada, malia que a diminución realízase a unha taxa moi semellante nas dúas series:

Taxa de variación créditos 2011/2008 $=2,387 / 2,430=0,98$.

Taxa de variación depósitos 2011/2008 =2,139/2,153 =0,99.

Así mesmo, os coeficientes de correlación ${ }^{2}$, calculados nos dous períodos, que se achegan na táboa seguinte corroboran as análises expostas:

Taboa 3. Coeficientes de correlación de créditos-tempo e depósitos-tempo. Períodos 2002-8 e 2008-11.

\begin{tabular}{|l|r|}
\hline Creditos/Tiempo & \\
\hline $2002-2008$ & 0,988 \\
\hline $2008-2011$ & $-0,656$ \\
\hline Depósitos/Tiempo & \\
\hline $2002-2008$ & 0,990 \\
\hline $2008-2011$ & $-0,714$ \\
\hline
\end{tabular}

Fonte: Elaboración propia a partir de datos da táboa 1 (Anexo)

Existe unha correlación directa moi elevada entre os créditos e o tempo e entre os depósitos e o tempo, no treito 2002-2008, volvéndose inversa, nos dous casos, no período 2008-2011, o que permite reforzar, dende outro punto de vista, a hipótese do cambio de tendencia.

De todas as análises expostas despréndense dúas conclusións:

1. O cambio na "tendencia" de crecemento, tanto nos créditos como nos depósitos, prodúcese no ano $2008^{3}$.

2. A partir do ano 2008, ao principio do período da crise, os créditos e os depósitos seguen unha tendencia de estancamento.

Por tanto:

No período 2002-2008, a tendencia tanto dos créditos como dos depósitos é crecente, resultado dunha economía de carácter expansivo.

No período 2008-2011 detéctase un cambio a partir do ano 2008 e un posterior estancamento das dúas variables. Este cambio prodúcese tamén na economía real. Confírmase, con isto, que o grao de crise bancaria está vencellado á crise financeira que ten a súa contrapartida nunha situación recesiva da economía real.

\section{Análise das Partidas do Balance Bancario Agregado}

\footnotetext{
${ }^{2}$ Coeficiente de correlación calculado como $\rho(\mathrm{x}, \mathrm{y})=\operatorname{cov}(\mathrm{x}, \mathrm{y}) /\left(\sigma(\mathrm{x})^{*} \sigma(\mathrm{y})\right)$, sendo $\mathrm{x}$ o tempo e e os créditos ou depósitos, en cada caso.

${ }^{3}$ Malia que o cambio comeza a mediados do ano 2007, a efectos de repercusión nos datos, non se percibe na información dispoñible ata o 2008.
} 
O obxectivo deste apartado é comprobar a composición dos balances agregados bancarios no período de análise, a fin de deixar de manifesto a súa evolución, e o cambio que se produce na estrutura dos devanditos balances como consecuencia da crise. Para iso, analizarase a composición do activo do balance agregado, do pasivo, e concluirase cun estudo de diferenzas.

\section{A. Análise do activo do balance}

I. Análise estática

Mediante a análise estática preténdese estudar os cambios nas variables que integran o activo, observando a súa evolución nun momento do tempo. Trátase, por tanto, dun estudo vertical de porcentaxes.

A táboa 4, no Anexo, recolle a síntese das partidas principais do activo do balance agregado das entidades financeiras, para observacións anuais. Deste modo, para o período 2002-2011 proporciónanse os importes do activo nas partidas, atendendo á desagregación que realiza o Banco de España (Banco de España. Boletín Estatístico, 2011):

$$
\begin{aligned}
& \text { - Crédito Interbancario } \\
& \text { - Créditos: } \\
& \text { o Administracións Públicas } \\
& \text { o Sector residente } \\
& \text { o } \quad \text { Resto do mundo } \\
& \text { - Valores distintos de accións e participacións } \\
& \text { o } \quad \text { Residentes en España } \\
& \text { o Sector exterior } \\
& \text { - Activos non sectorizados } \\
& \text { o Efectivo }
\end{aligned}
$$

o Outros

- Accións e participacións

$$
\begin{aligned}
& \text { o Residentes en España } \\
& \text { o Resto do mundo } \\
& \text { - Dubidosos } \\
& \text { - Morosos }
\end{aligned}
$$

Para unha análise xeral da evolución, obsérvanse primeiro as partidas globais, que se resumen na táboa 5 , e que recolle os datos do "resumo de partidas globais do activo". Os datos son anuais, para o período 2002-2011:

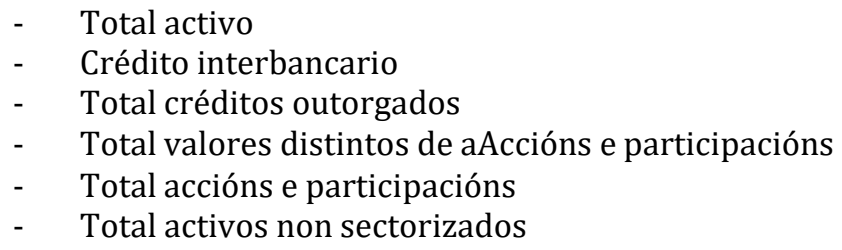

A evolución destas partidas permite afirmar que malia que en termos absolutos todas elas crecen dende o ano 2002 ata o ano 2011, obsérvase un cambio de tendencia no momento no que se identifica a crise. 0 gráfico achegado permite visualizar a situación.

Gráfico 2: Evolución das Partidas Globais do Activo. Datos anuais para o período 2002-2011. (Base: Táboa 5). Miles de millóns de euros 


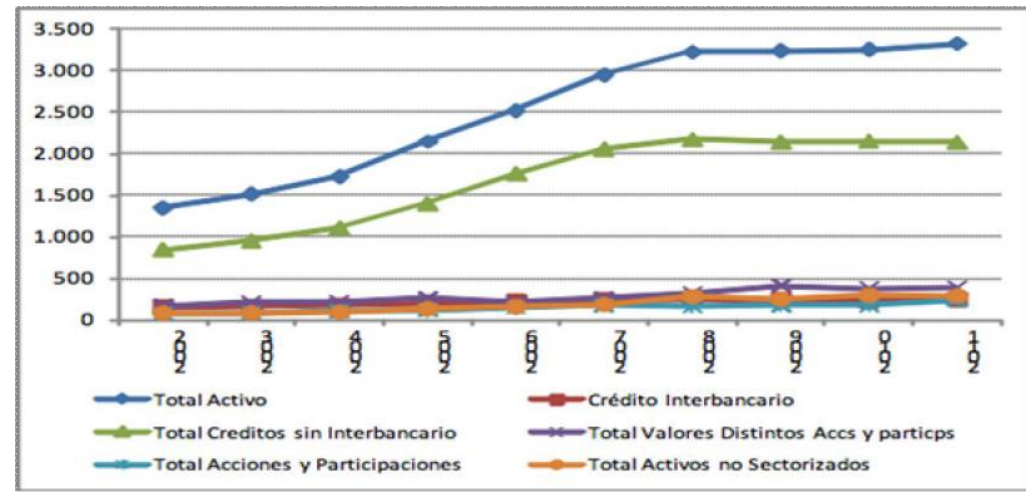

Obsérvase para o activo o cambio de tendencia a partir do ano 2008.

Para analizar os valores de tendencia durante o período da análise úsase a ferramenta estatística de "liña" e "liña de tendencia", que se vai aplicar soamente á variable "créditos" (sen interbancario). Isto realízase nos dous subperíodos, e os resultados represéntanse nos gráficos seguintes, que incorporan tamén as ecuacións de axuste e abondade de cada un deles: Os gráficos 3 e 4 de liña de tendencia amosan que o axuste linear éválido para o primeiro período, anterior á crise, na medida que no da crise, o axuste a unha función polinómica (definida nos gráficos) amósase máis axeitado.

Gráfico 3: Liña e liña de tendencia de créditos no período 2002-2008. Base: táboa 5.

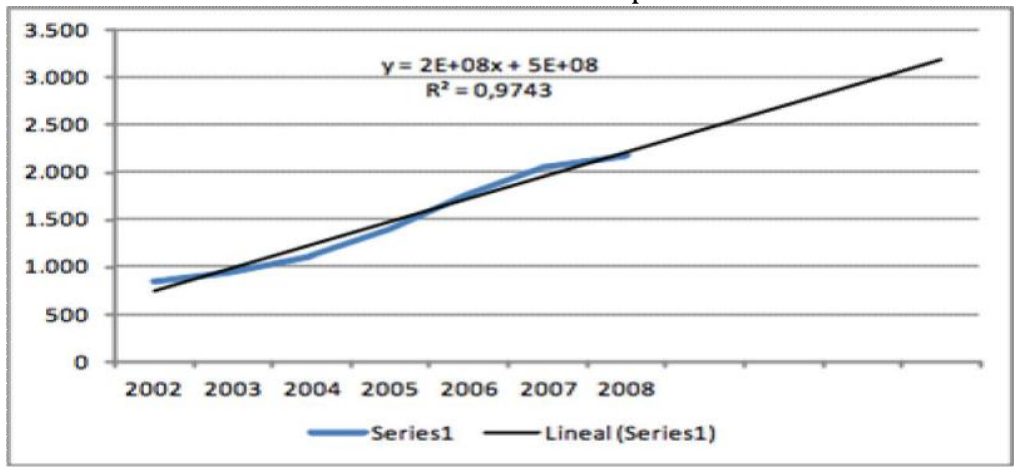

Gráfico 4: Liña e liña de tendencia de créditos para o período 2008-2011. Base: táboa 5

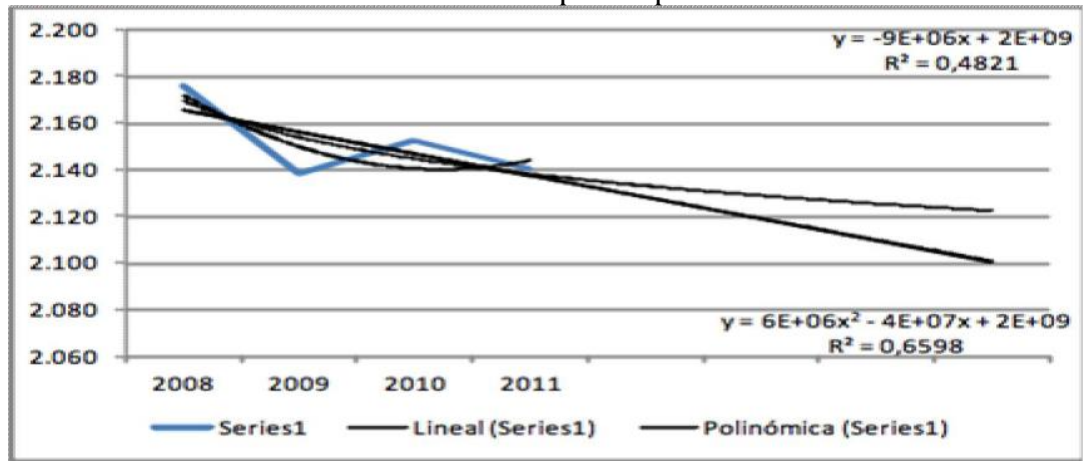

Os dous períodos nos que se dividiron a análise polo cambio de tendencia, 2002-2008 e 2008-2011, proporcionan unha maior precisión nas evolucións, que se resumen na 
táboa 2.10, que contén as porcentaxes para os diferentes compoñentes principais do activo, calculando o seu valor absoluto sobre o valor total do activo para cada ano. A partir destas porcentaxes, analízase a situación para o primeiro ano de estudo (2002) e para o último (2011). Así, no ano 2002, os créditos, cun 74,20\%, constitúen a partida máis importante do activo do balance, namentres que no ano 2011, obsérvase unha distribución das partidas diferentes, acadando os créditos un $72,06 \%$, e que pasan ao resto dos compoñentes, especialmente Accións e Activos non sectorizados, os incrementos provocados pola diminuición dos créditos. Os gráficos 5 e 6 amosan estas distribucións.

Gráfico 5: Distribución das partidas do activo en 2002 por porcentaxes. (Base: Táboa 6 no Anexo).

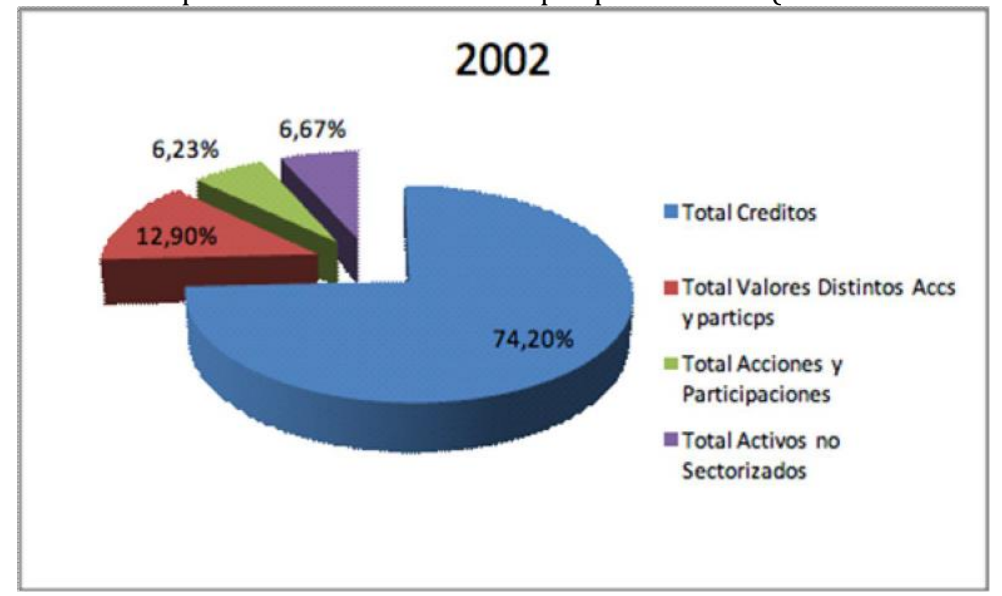

Gráfico 6: Distribución das partidas do activo en 2011 por porcentaxes. (Base: Táboa 6).

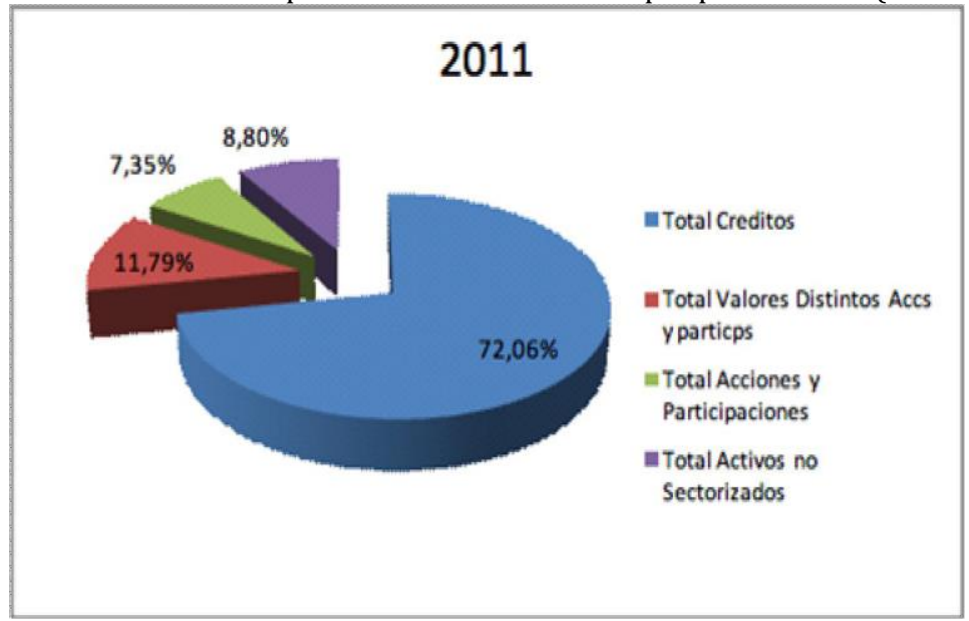

II. Análise dinámica

O obxectivo da análise dinámica é estudar os cambios nas variables que integran o activo, observando a súa evolución entre os dous momentos ou períodos temporais. Trátase, por tanto, dun estudo horizontal de porcentaxes mediante as diferenzas. Este permite observar as variacións que experimenta cada partida nun período, ao restar o valor de cada un dos compoñentes principais do activo no último ano e o valor no primeiro ano do período considerado. 
Asemade, as porcentaxes calculadas sobre estas diferenzas ofrecen unha visualización clara das evolucións dos compoñentes.

A táboa 7 recolle as porcentaxes relativas ás diferenzas das partidas globais do Activo, nos dous períodos obxecto de consideración:

Táboa 7: Porcentaxes das diferenzas dos valores do activo, por subperíodos.

\begin{tabular}{|r|r|r|r|r|r} 
& $\begin{array}{c}\text { Crédito } \\
\text { Interbancario }\end{array}$ & $\begin{array}{c}\text { Total } \\
\text { Creditos sin } \\
\text { interbancario }\end{array}$ & $\begin{array}{c}\text { Total Valores } \\
\text { Distintos Accs y } \\
\text { particps }\end{array}$ & $\begin{array}{c}\text { Total Acciones y } \\
\text { Participaciones }\end{array}$ & $\begin{array}{c}\text { Total Activos no } \\
\text { Sectorizados }\end{array}$ \\
\hline $2008-2002$ & $5,8 \%$ & $71,0 \%$ & $8,1 \%$ & $4,7 \%$ & $10,5 \%$ \\
\hline $2011-2008$ & $-7,6 \%$ & $-35,6 \%$ & $65,8 \%$ & $71,8 \%$ & $5,6 \%$ \\
\hline
\end{tabular}

Como se pode observar a partir das análises anteriores, a crise marca unha redistribución total das partidas, deixando de manifesto que:

0 total de créditos outorgados (non inclúen os interbancarios) experimenta un crecemento dun $71 \%$ do activo no período anterior á crise, en tanto que sofre un decrecemento do 35,6\% nos anos que se identifican coa crise.

A variación na cifra dos créditos é asumida polo resto de partidas do activo do balance, en particular por "accións e participacións" e por "valores distintos de "accións e participacións".

0 gráfico 7 reflicte as variacións citadas.

Gráfico 7: Variación das porcentaxes das partidas globais do activo nos períodos 2002-2008 e 2008-2011. (Base: Táboa 7)

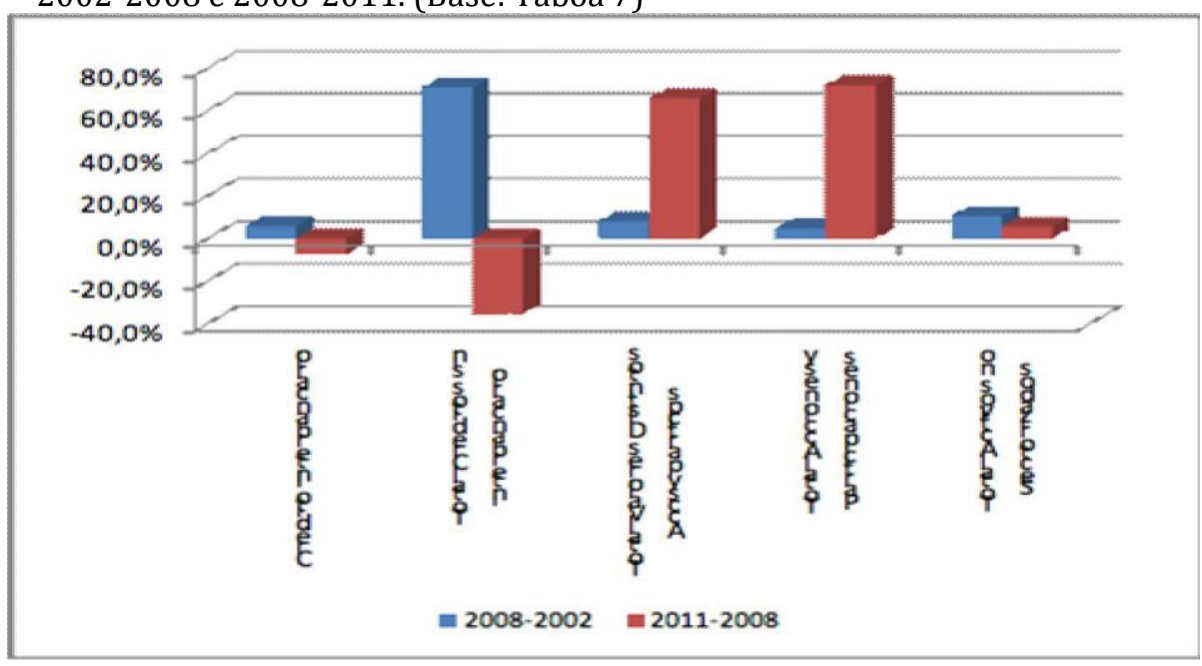

\section{A taxa de morosidade dos datos agregados}

Os cálculos relativos á taxa de morosidade, como ratio entre o valor da cifra de morosos, para cada ano, e o dos créditos, para ese mesmo período de tempo, atópanse recollidos na táboa 8 . Tamén recolle o cálculo do gap, como diferenza entre créditos e depósitos, e o gap axustado ou corrixido, como resultado neto do valor esperado dos créditos 
(créditos - taxa de morosidade x créditos) e os depósitos. 0 gráfico 8 amosa a evolución do gap e o gap axustado, permitindo observar o desprazamento ocorrido no período da crise.

Gráfico 8: Evolución gap e gap corrixido no período 2002-2011. Base: táboa 8. Millóns de euros

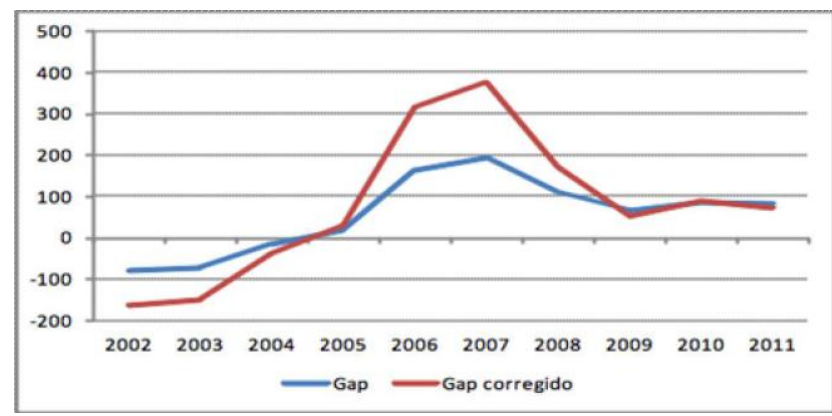

Os coeficientes de correlación entre a taxa de morosidade e o gap ofrécense na táboa 9, e o gráfico 9 permite ver o diferente comportamento nos dous períodos.

Táboa 9: Coeficientes de correlación entre taxa de morosidade e medidas do Gap, nos períodos 20022008 e $2008-2011$.

\begin{tabular}{|l|l|r|}
\hline & \multicolumn{1}{|c|}{ Gap } & \multicolumn{1}{c|}{$\begin{array}{c}\text { Gap } \\
\text { corregido }\end{array}$} \\
\hline $2002 / 2008$ & 0,1946 & 0,0500 \\
\hline $2008-2011$ & 0,7796 & $-0,9235$ \\
\hline
\end{tabular}

Gráfico 9: Coeficientes de correlación entre a taxa de morosidade e gap e gap corrixido. Base: táboa 9.

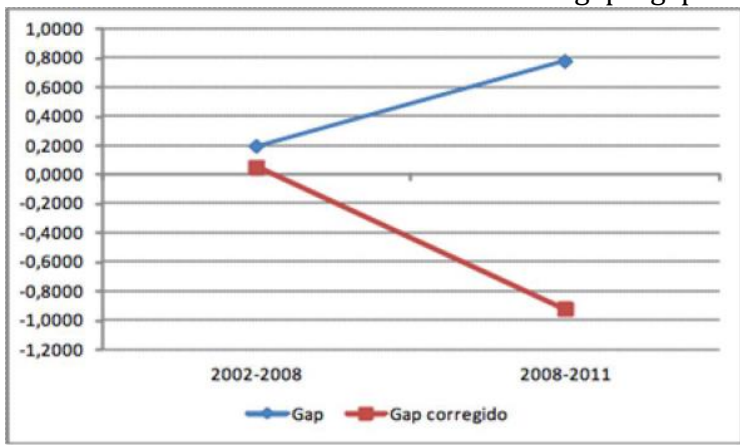

Os resultados da análise indican que a taxa de morosidade marca tamén a existencia de dous períodos temporais claramente definidos e diferenciados:

No período 2002-2008, a taxa de morosidade e o gap están feblemente correlacionados, xa que no período da crise, ese coeficiente de correlación elévase fortemente.

No período anterior á crise, a taxa de morosidade e o gap corrixido mantén un valor moi feble de correlación, namentres que a partir do ano 2008 pasa a un valor elevado negativo, aspecto indicativo do cambio de tendencia.

\section{B. Análise do pasivo do balance}

\section{Análise estatística}

Igual que no activo, analízanse os cambios nas variables que integran o pasivo mediante un estudo vertical de porcentaxes. 
A táboa 10 do anexo recolle a síntese das partidas principais do pasivo do balance agregado das entidades financeiras, atendendo á desagregación que realiza o Banco de España (Boletín Estatístico, 2011), para observacións anuais. Para o período anual 2002- 2011 proporciónanse os importes do pasivo para as epígrafes referidos a:

Depósitos:

o Depósitos residentes España

o Depósitos RE interbancario

o Depósitos administracións públicas

o Depósitos outros sectores residentes

o Depósitos sector exterior

- Pasivos non sectorizados:

o Valores distintos de accións e participacións

o Capital e reservas

o Obra benéfico social

o Outros pasivos

A táboa 11 proporciona os mesmos datos, separando o valor dos depósitos procedentes dos interbancario, a efectos de posteriores análises homoxéneas co tratamento realizado para os créditos.

A táboa 12 resume as principais epígrafes do pasivo agregado para o período 20022011, que se articulan en torno a:

$\begin{array}{ll}\text { - } & \text { Depósitos } \\ \text { - } & \text { Valores distintos de accións e participacións } \\ \text { - } & \text { Obra benéfico social } \\ \text { - } & \text { Outros pasivos }\end{array}$

E a táboa 13 amosa os mesmos conceptos, cos depósitos interbancario independentes do valor global dos depósitos. 0 gráfico 10 amosa a evolución no tempo das variables de pasivo, separando o efecto da partida de interbancario.

Gráfico 10: Evolución no tempo das variables de pasivo. Datos anuais, período 2002-2011. Base: táboa 13.

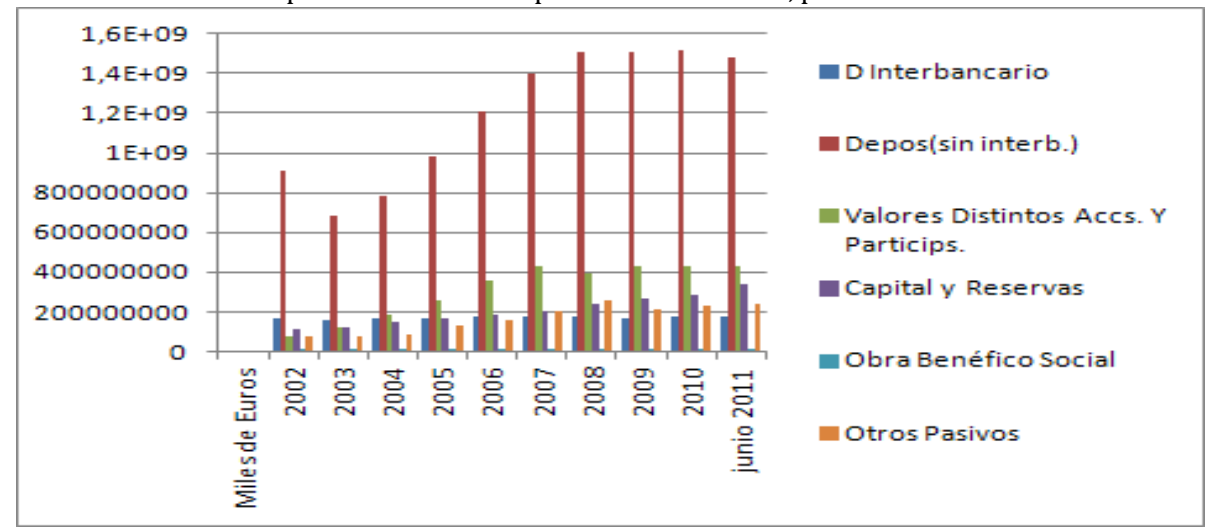

Obsérvase para o pasivo o cambio de tendencia, do crecemento ao estancamento, en todos os compoñentes, a partir do ano 2008. 
Para analizar os valores de tendencia durante o período da análise, utilízase a ferramenta estatística de "liña" e "liña de tendencia", que se vai aplicar soamente á variable "depósitos" (sen interbancario), xa que é a de maior representatividade cuantitativa no pasivo. Isto realizarase nos dous subperíodos, e os resultados represéntanse nos gráficos seguintes, que incorporan tamén as ecuacións de axuste e a bondade de cada unha delas:

Gráfico 11: Liña e liña de tendencia de “depósitos” no período 2002-2008. Base: táboa 13. Miles de millóns de euros

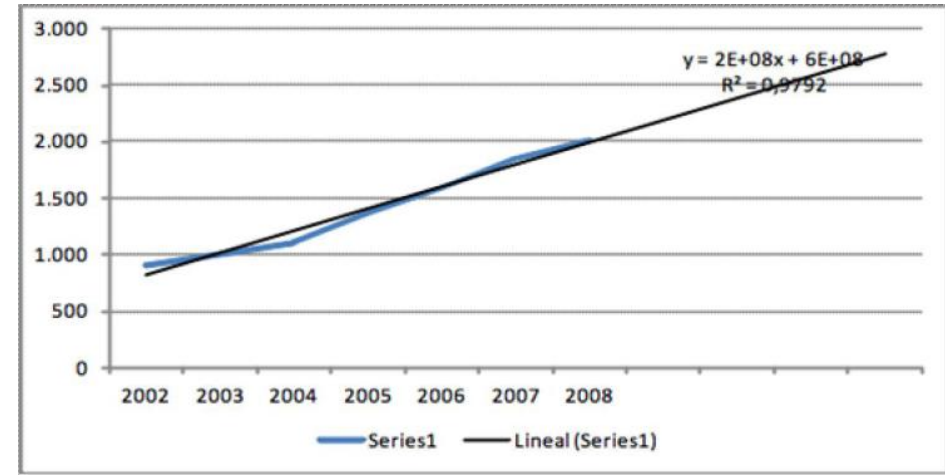

Gráfico 12: Liña e liña de tendencia “depósitos” en 2008-2011. Base: táboa 13

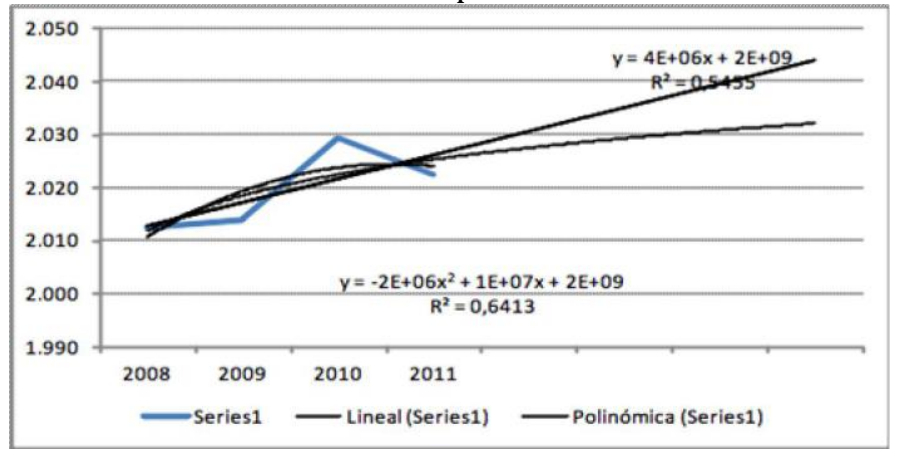

Como no caso do activo todas e cada unha das partidas globais do pasivo do balance crecen dende o ano 2002 ata o ano 2011, malia que se pode observar un cambio en valores relativos dende o momento no que se identifica a crise.

Os dous períodos nos que se dividiu a análise, 2002-2008 e 2008-2011 permiten detectar as evolucións con maior precisión. Estas resúmense na táboa 14, de valores en porcentaxes para os distintos compoñentes principais do pasivo, derivándose a baixada acusada de "depósitos", dende 2002 a 2011, compensada polo crecemento moderado de "capital e reservas" e "doutros pasivos".

Este estudo de porcentaxes adquire unha mellor interpretación a través da análise estática, en 2002 e 2011, e da análise dinámica por diferenzas, como se fixo no caso do activo. Así, no ano 2002 pódese observar que os depósitos, cun 67,27 de porcentaxe, é a partida máis importante do pasivo do balance, namentres no ano 2011 os depósitos chegan atan só o 60,8\% do pasivo total, sendo compensado este descenso polo aumento doutras partidas como capital e reservas e por valores distintos de accións e participacións. Os gráficos 2.16.1 e 2.16.2 resumen esta situación. 
Gráfico 13: Distribución das partidas do pasivo en 2002 por porcentaxes. (Base: Táboa 14).

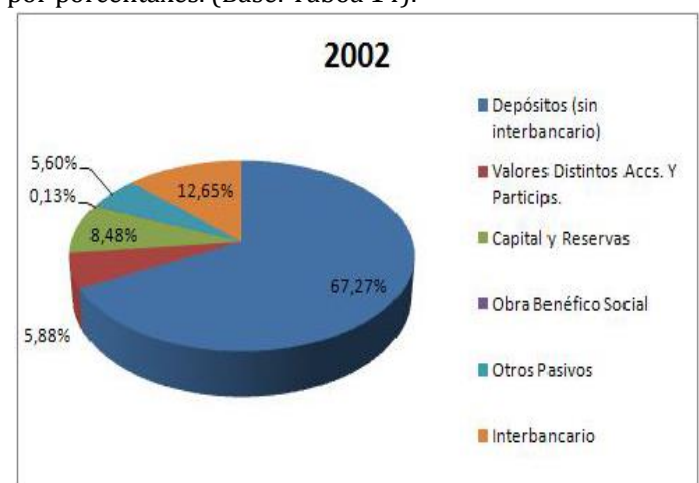

Gráfico 14: Distribución das partidas do pasivo en 2011 por porcentaxes. (Base: Táboa 14).

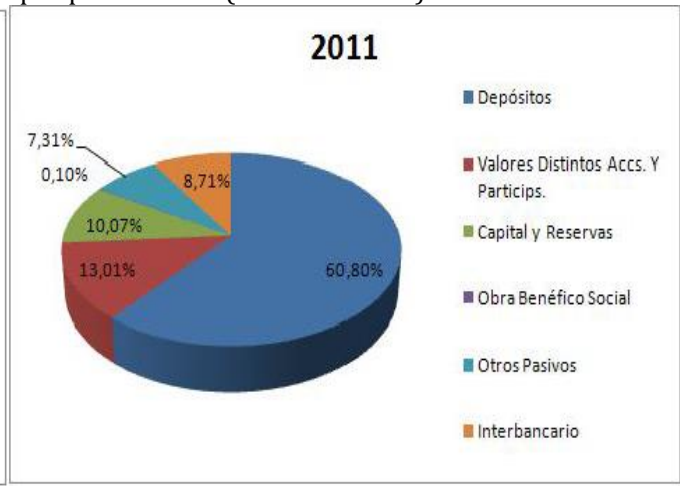

Análise dinámica

Como no caso do activo, estúdanse os cambios nas variables que integran o pasivo, mediante un estudo horizontal de porcentaxes a través das diferenzas.

A táboa 15 do anexo, que se reproduce aquí, recolle as porcentaxes relativas ás diferenzas das partidas globais do pasivo, nos dous períodos obxecto de estudo:

Táboa 15: Porcentaxes das diferenzas dos valores do pasivo, por subperíodos.

\begin{tabular}{|r|r|r|r|r|r|r|}
\hline & D Interbanca Depos(sin in Valores Disti Capital y Res Obra Benéfic Otros Pasivo \\
\hline $2008-2002$ & $7,7 \%$ & $58,9 \%$ & $16,9 \%$ & $6,8 \%$ & $0,1 \%$ & $9,6 \%$ \\
\hline $2011-2008$ & $-24,7 \%$ & $9,5 \%$ & $36,5 \%$ & $90,3 \%$ & $0,3 \%$ & $-11,9 \%$ \\
\hline
\end{tabular}

Como se pode observar a partir dos datos, a crise marca unha redistribución total das partidas do pasivo, deixando de manifesto que:

0 total dos depósitos (sen interbancario) experimenta un crecemento próximo ao $60 \%$ no período anterior á crise, namentres que sofre un descenso ata o 9,5\% nos anos que se identifican coa crise. A variación na cifra dos depósitos é asumida polo resto das partidas do balance, en particular por capital e reservas e por valores distintos deaccións e participacións. 0 gráfico 15 reflicte esta información.

Gráfico 15: Variación das porcentaxes das partidas globais do pasivo nos períodos 2002-2008 e 20082011. (Base: Táboa 15).

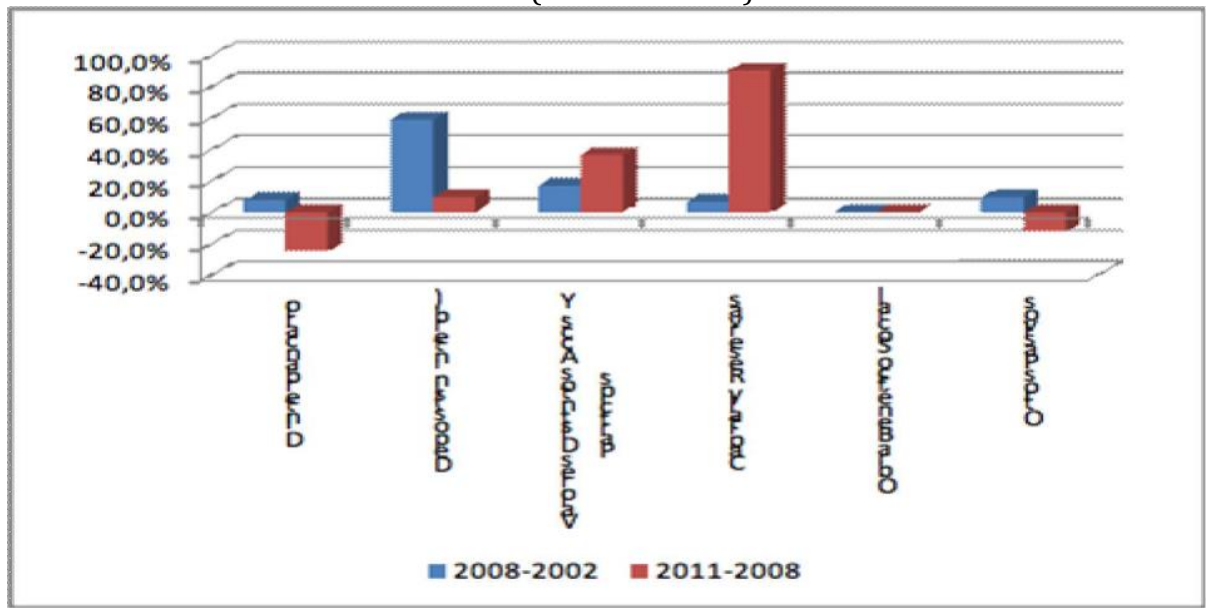


Así mesmo, a partir dos datos obtidos do Boletín Estatístico do Banco de España (2011), dos que se extrae unha primeira información da evolución dos dubidosos e dos créditos dende o ano 2002 ata o ano 2011, a evolución no período marzo 2002-2011 do total dos créditos e o total de dubidosos, por trimestres, permite observar un gap crecente dos dubidosos con respecto aos créditos. A evolución da taxa de morosidade, en sentido amplo, a partir da cifra de dubidosos sobre créditos, e tamén a evolución da taxa de crecemento de créditos en cada ano, rexistra unha taxa de dubidosos sobre o total de créditos dun 1,23\% en marzo de 2002 ao 6,69\% en 2011.

\section{Conclusións}

Da análise descritiva do comportamento das principais partidas do balance das entidades bancarias en España derívase que:

a) Con respecto á evolución de créditos e depósitos (negocio bancario):

O cambio na tendencia de crecemento, tanto nos créditos como nos depósitos, prodúcese no ano 2008, tal como confirman os coeficientes de correlación.

No período 2002-2008, a tendencia tanto dos créditos como dos depósitos é crecente, resultado dunha economía de carácter expansivo.

No período 2008-2011 detéctase un cambio de tendencia a partir do ano 2008 e un posterior estancamento das dúas variables. Este feito confirma que a crise bancaria está vencellada á crise financeira, que á súa vez ten a súa contrapartida nunha situación recesiva da economía real.

b) Con respecto ao balance bancario agregado

b.1. Con respecto ao activo

0 total de créditos outorgados experimenta un crecemento dun $71 \%$ do activo no período anterior á crise, namentres que sofre unha baixada do 35,6\% nos anos que se identifican co desencadeamento e o desenvolvemento da crise.

O descenso na cifra dos créditos é asumido polo resto das partidas do activo do balance, en particular por "accións e participacións" e por "valores distintos de accións e participacións". A taxa de morosidade marca tamén a existencia de dous períodos temporais claramente definidos e diferenciados:

De 2002 a 2008, no que mantén unha tendencia estable, con valores sempre por debaixo da unidade.

De 2008 a 2011, no que se produce un cambio de tendencia, e pasa a valores sempre por enriba da unidade, e continuamente crecentes no tempo.

b.2. Con respecto ao pasivo

O total dos depósitos experimenta un crecemento dun $66,6 \%$ no período anterior á crise, namentres sofre un descenso do 15,3\% con respecto ao período anterior nos anos que se identifican coa crise.

A variación na cifra dos depósitos é asumida polo resto das partidas do Balance, en particular por "capital e reservas" e por "valores distintos de accións e participacións".

A conclusión da análise empírica descritiva das magnitudes agregadas do sistema bancario español no período 2002-2011 é que existe un alto grao de prociclicidade, tanto no comportamento do negocio bancario como nos indicadores básicos do mesmo e dos seus riscos, e da taxa de morosidade, identificándose así a crise financeira. As conclusións extraídas da análise empírica do sistema bancario no período anterior e posterior ao comezo da crise confirman que o tratamento da xestión de risco bancario e de crédito deberá incluír non só a consideración das variables que afectan ao debedor, senón tamén as vencelladas á economía, os seus ciclos, factores xeográficos, sectoriais e, en xeral, todas a variables 
externas que inciden sobre o risco malia que non pertenzan ao ámbito interno das xestións das entidades financeiras.

\section{Bibliografía}

Banco de España. Boletín Estadístico, 2012, junio.

Banco de España. Boletín Estadístico, 2011.

Cibran Ferraz, Mํㅜ Pilar. Gestión Financiera. Teoría y casos prácticos. Ed. Tórculo. Santiago de Compostela, 2005.

Crespo Cibran, Miguel Ángel. Análisis del riesgo de crédito. Propuesta de gestión mediante un modelo de carteras sectorial. Tesis Doctoral. Universidad de Vigo, Vigo, 2013.

Pisón Fernández, Irene. Pisón Fernández, I. (2001). Dirección y Gestión Financiera de la Empresa. Ed. Pirámide. Madrid.

\section{Anexo Táboas.}

Táboa 1: Valores de Créditos e Depósitos. Datos anuais para o período 2002-2011. (miles de euros)

\begin{tabular}{|r|c|c|}
\hline \multicolumn{1}{|c|}{ AN } & Créd itos & Depó sito s \\
\hline 2002 & 1.003 .541 .521 & 1.080 .754 .979 \\
\hline 2003 & 1.121 .860 .685 & 1.192 .661 .246 \\
\hline 2004 & 1.292 .091 .178 & 1.307 .744 .906 \\
\hline 2005 & 1.611 .954 .573 & 1.592 .917 .088 \\
\hline 2006 & 1.982 .222 .032 & 1.819 .699 .009 \\
\hline 2007 & 2.303 .672 .948 & 2.107 .749 .353 \\
\hline 2008 & 2.439 .202 .545 & 2.327 .571 .665 \\
\hline 2009 & 2.385 .126 .331 & 2.318 .985 .107 \\
\hline 2010 & 2.386 .644 .416 & 2.298 .890 .250 \\
\hline 2011 & 2.395 .558 .699 & 2.311 .929 .094 \\
\hline
\end{tabular}

Táboa 2: Taxas de crecemento dos créditos e dos depósitos. Datos anuais para o período 2002-11 (Base 1 , ano 2002)

\begin{tabular}{|r|r|r|}
\hline A N O & Cré dito & De pó sito s \\
\hline 2002 & 1,0000 & 1,0000 \\
\hline 2003 & 1,1179 & 1,1035 \\
\hline 2004 & 1,2875 & 1,2100 \\
\hline 2005 & 1,6063 & 1,4739 \\
\hline 2006 & 1,9752 & 1,6837 \\
\hline 2007 & 2,2955 & 1,9503 \\
\hline 2008 & 2,4306 & 2,1537 \\
\hline 2009 & 2,3767 & 2,1457 \\
\hline 2010 & 2,3782 & 2,1271 \\
\hline 2011 & 2,3871 & 2,1392 \\
\hline
\end{tabular}


Táboa 3. Coeficientes de correlación de créditos-tempo e depósitos-tempo. Periodos 2002-2008 e 2008-2011

\section{Créditos/Tiempo}

$2002-2008$

0,988

$2008-2011$

$-0,656$

Depósitos/Tiempo

$2002-2008$

0,990

$2008-2011$

$-0,714$

Táboa 4. Detalle de partidas do activo. Datos anuais para o período 2002-2011 (miles de euros)

\begin{tabular}{|l|l|l|l|l|l|l|l|l|l|}
\hline & TotalActivo & $\begin{array}{l}\text { Crédito } \\
\text { interbancario }\end{array}$ & Tota ICreditos & $\begin{array}{l}\text { Cr. } \\
\text { Resientes. } \\
\text { AA.PP. }\end{array}$ & $\begin{array}{l}\text { Cr. } \\
\text { Resientes. } \\
\text { OSR }\end{array}$ & $\begin{array}{l}\text { Cr. } \\
\text { Resto } \\
\text { Mundo }\end{array}$ & $\begin{array}{l}\text { Total } \\
\text { Valores } \\
\text { Distintos } \\
\text { Accs y } \\
\text { particps }\end{array}$ & $\begin{array}{l}\text { Valores } \\
\text { Distintos de } \\
\text { acciones y } \\
\text { participaciones. } \\
\text { Residentes } \\
\text { España }\end{array}$ \\
\hline 2002 & 1.352 .405 .828 & 155.304 .738 & 848.236 .783 & 33.102 .022 & 701.663 .076 & 113.471 .685 & 174.493 .407 & $\begin{array}{l}\text { Valores } \\
\text { Distintos de } \\
\text { acciones y } \\
\text { participaciones. } \\
\text { S. Exterior }\end{array}$ \\
\hline 2003 & 1.514 .634 .884 & 167.420 .000 & 954.440 .685 & 35.584 .831 & 802.212 .448 & & & \\
\hline 2004 & 1.727 .212 .011 & 184.895 .235 & 1.107 .195 .943 & 37.638 .842 & & & \\
\hline 2005 & 2.149 .666 .155 & 209.552 .263 & 1.402 .402 .310 & & & & \\
\hline 2006 & 2.517 .121 .128 & 224.051 .569 & & & & & \\
\hline 2007 & 2.946 .498 .758 & 263.091 .266 & & & & & \\
\hline 2008 & 3.223 .715 .704 & 246.806 .457 & & & & & \\
\hline 2009 & 3.238 .236 .359 & 246.806 .457 & & & & & \\
\hline 2010 & 3.251 .534 .538 & 234.095 .485 & & & & & \\
\hline 2011 & 3.324 .589 .740 & 255.392 .415 & & & & & \\
\hline
\end{tabular}

Táboa 5: Resumo de partidas globais do activo. Datos anuais para o período 2002-2011

\begin{tabular}{|r|r|r|r|r|r|r|}
\hline & Total Activo & $\begin{array}{c}\text { Crédito } \\
\text { Interbanc ario }\end{array}$ & Total Creditos & $\begin{array}{c}\text { Total Valores } \\
\text { Dis tintos Accs y } \\
\text { partic ps }\end{array}$ & $\begin{array}{c}\text { Total Acciones y } \\
\text { P articipac iones }\end{array}$ & $\begin{array}{c}\text { Total Activos no } \\
\text { S ec toriz ados }\end{array}$ \\
\hline & & & & & & \\
\hline 2002 & 1.352 .405 .828 & 155.304 .738 & 848.236 .783 & 174.493 .407 & 84.195 .356 & 90.175 .544 \\
\hline 2003 & 1.514 .634 .884 & 167.420 .000 & 954.440 .685 & 213.739 .867 & 87.898 .325 & 91.136 .008 \\
\hline 2004 & 1.727 .212 .011 & 184.895 .235 & 1.107 .195 .943 & 221.905 .904 & 114.426 .928 & 98.788 .001 \\
\hline 2005 & 2.149 .666 .155 & 209.552 .263 & 1.402 .402 .310 & 269.772 .150 & 124.276 .384 & 143.663 .050 \\
\hline 2006 & 2.517 .121 .128 & 224.051 .569 & 1.758 .170 .463 & 219.753 .776 & 151.889 .249 & 163.256 .075 \\
\hline 2007 & 2.946 .498 .758 & 246.129 .025 & 2.057 .543 .923 & 267.908 .917 & 183.617 .428 & 191.299 .461 \\
\hline 2008 & 3.223 .715 .704 & 263.091 .266 & 2.176 .111 .279 & 325.706 .120 & 171.891 .708 & 286.915 .333 \\
\hline 2009 & 3.238 .236 .359 & 246.806 .457 & 2.138 .319 .874 & 415.445 .278 & 184.051 .169 & 253.613 .576 \\
\hline 2010 & 3.251 .534 .538 & 234.095 .485 & 2.152 .548 .931 & 383.761 .390 & 180.477 .290 & 300.651 .446 \\
\hline 2011 & 3.324 .589 .740 & 255.392 .415 & 2.140 .166 .284 & 392.114 .852 & 244.326 .744 & 292.589 .443 \\
\hline
\end{tabular}

Táboa 6: Porcentaxes dos compoñentes principais do activo. Datos anuais para o período 2002-xuño 2011

\begin{tabular}{|l|l|c|c|c|c|c|}
\hline & Total Activo & $\begin{array}{c}\text { Crédito } \\
\text { Interbancario }\end{array}$ & Total Creditos & $\begin{array}{c}\text { Total Valores } \\
\text { Distintos Accs y } \\
\text { particps }\end{array}$ & $\begin{array}{c}\text { Total Acciones y } \\
\text { Participaciones }\end{array}$ & $\begin{array}{c}\text { Total Activos no } \\
\text { Sectorizados }\end{array}$ \\
\hline 2002 & $100,00 \%$ & $11,48 \%$ & $62,72 \%$ & $12,90 \%$ & $6,23 \%$ & $6,67 \%$ \\
\hline 2003 & $100,00 \%$ & $11,05 \%$ & $63,01 \%$ & $14,11 \%$ & $5,80 \%$ & $6,02 \%$ \\
\hline 2004 & $100,00 \%$ & $10,70 \%$ & $64,10 \%$ & $12,85 \%$ & $6,62 \%$ & $5,72 \%$ \\
\hline 2005 & $100,00 \%$ & $9,75 \%$ & $65,24 \%$ & $12,55 \%$ & $5,78 \%$ & $6,68 \%$ \\
\hline 2006 & $100,00 \%$ & $8,90 \%$ & $69,85 \%$ & $8,73 \%$ & $6,03 \%$ & $6,49 \%$ \\
\hline 2007 & $100,00 \%$ & $8,35 \%$ & $69,83 \%$ & $9,09 \%$ & $6,23 \%$ & $6,49 \%$ \\
\hline 2008 & $100,00 \%$ & $8,16 \%$ & $67,50 \%$ & $10,10 \%$ & $5,33 \%$ & $8,90 \%$ \\
\hline 2009 & $100,00 \%$ & $7,62 \%$ & $66,03 \%$ & $12,83 \%$ & $5,68 \%$ & $7,83 \%$ \\
\hline 2010 & $100,00 \%$ & $7,20 \%$ & $66,20 \%$ & $11,80 \%$ & $5,55 \%$ & $9,25 \%$ \\
\hline 2011 & $100,00 \%$ & $7,68 \%$ & $64,37 \%$ & $11,79 \%$ & $7,35 \%$ & $8,80 \%$ \\
\hline
\end{tabular}

Táboa 7. Porcentaxes das diferenzas dos valores do activo, por subperíodos

\begin{tabular}{|c|c|c|c|c|c|}
\hline & $\begin{array}{c}\text { Crédito } \\
\text { interbancario }\end{array}$ & $\begin{array}{c}\text { Total } \\
\text { créditos sin } \\
\text { interbancario }\end{array}$ & $\begin{array}{c}\text { Total valores } \\
\text { Distintos Accs } y \\
\text { particps. }\end{array}$ & $\begin{array}{c}\text { Total acciones } \\
\text { participaciones }\end{array}$ & $\begin{array}{c}\text { Total activos no } \\
\text { sectorizados }\end{array}$ \\
\hline $2008-2002$ & $5,8 \%$ & $71,0 \%$ & $8,1 \%$ & $4,7 \%$ & $10,5 \%$ \\
\hline $2011-2008$ & $-7,6 \%$ & $-35,6 \%$ & $65,8 \%$ & $71,8 \%$ & $5,6 \%$ \\
\hline
\end{tabular}


Táboa 8: Taxa de morosidade e "gap". Datos anuais para o período 2002-2011

\begin{tabular}{|l|c|r|r|r|r|r|r|r|r|}
\hline AÑOS & \multicolumn{1}{|c|}{ Créditos } & \multicolumn{1}{c|}{ Dudosos } & Morosos & Moros/Dud & $\begin{array}{c}\text { Tasa } \\
\text { morosidad }\end{array}$ & $\begin{array}{r}\text { Valor Esperado } \\
\text { Créditos }\end{array}$ & Depósitos & Gap & Gap corregido \\
\hline 2002 & 1.003 .541 .521 & 9.418 .702 & 6.969 .839 & 0,7400 & $0,695 \%$ & 996.571 .682 & 1.080 .754 .979 & -77.213 .458 & -84.183 .297 \\
\hline 2003 & 1.121 .860 .685 & 9.529 .012 & 7.060 .998 & 0,7410 & $0,629 \%$ & 1.114 .799 .687 & 1.192 .661 .246 & -70.800 .561 & -77.861 .559 \\
\hline 2004 & 1.292 .091 .178 & 9.230 .944 & 6.738 .589 & 0,7300 & $0,522 \%$ & 1.285 .352 .589 & 1.307 .744 .906 & -15.653 .728 & -22.392 .317 \\
\hline 2005 & 1.611 .954 .573 & 10.479 .674 & 7.764 .000 & 0,7409 & $0,482 \%$ & 1.604 .190 .573 & 1.592 .917 .088 & 19.037 .485 & 11.273 .485 \\
\hline 2006 & 1.982 .222 .032 & 11.626 .285 & 8.996 .000 & 0,7738 & $0,454 \%$ & 1.973 .226 .032 & 1.819 .699 .009 & 162.523 .023 & 153.527 .023 \\
\hline 2007 & 2.303 .672 .948 & 17.147 .220 & 14.063 .000 & 0,8201 & $0,610 \%$ & 2.289 .609 .948 & 2.107 .749 .353 & 195.923 .595 & 181.860 .595 \\
\hline 2008 & 2.439 .202 .545 & 65.617 .408 & 52.102 .000 & 0,7940 & $2,136 \%$ & 2.387 .100 .545 & 2.327 .571 .665 & 111.630 .880 & 59.528 .880 \\
\hline 2009 & 2.385 .126 .331 & 96.846 .384 & 79.463 .000 & 0,8205 & $3,332 \%$ & 2.305 .663 .331 & 2.318 .985 .107 & 66.141 .224 & -13.321 .776 \\
\hline 2010 & 2.386 .644 .416 & 111.014 .400 & 87.078 .512 & 0,7844 & $3,649 \%$ & 2.299 .565 .904 & 2.298 .890 .250 & 87.754 .166 & 675.654 \\
\hline 2011 & 2.395 .558 .699 & 125.082 .860 & 94.306 .528 & 0,7540 & $3,937 \%$ & 2.301 .252 .171 & 2.311 .929 .094 & 83.629 .605 & -10.676 .923 \\
\hline
\end{tabular}

Táboa 9- Coeficientes de correlación entre taxa de morosidade e medidas do gap nos períodos 2002-2008 e 2008-2011

\begin{tabular}{|c|c|c|}
\hline & Gap & $\begin{array}{c}\text { Gap } \\
\text { corregido }\end{array}$ \\
\hline $2002-2008$ & 0,1946 & 0,0500 \\
\hline $2008-2011$ & 0,7796 & $-0,9235$ \\
\hline
\end{tabular}

Táboa 10: Detalle de partidas do pasivo. Datos anuais para o período 2002-2011.

\begin{tabular}{|c|c|c|c|c|c|c|c|c|c|c|c|}
\hline & TotalPasivo & Depósitos & Resid. España & Interbancario & RE. AA.PP. & RE. OSR & SectorExterior & $\begin{array}{l}\text { Valores } \\
\text { Distintos } \\
\text { Accs.Y } \\
\text { Particips. }\end{array}$ & $\begin{array}{l}\text { Capital y } \\
\text { Reservas }\end{array}$ & $\begin{array}{c}\text { Obra } \\
\text { Benéfico } \\
\text { Social }\end{array}$ & $\begin{array}{l}\text { Otros } \\
\text { Pasivo } \\
\mathrm{s}\end{array}$ \\
\hline 2.002 & 1.352 .406 .082 & 909.727 .930 & 805.843 .415 & 171.027.049 & 40.016 .030 & 594.800 .336 & 274.911.564 & 79.516.191 & 114.664 .620 & 1.737 .692 & 75.732 .600 \\
\hline 2.003 & 1.514 .635 .060 & 998.986 .533 & 872.733 .260 & 193.674 .713 & 35.254 .592 & 643.803 .955 & 319.927 .986 & 120.331 .311 & 122.480 .060 & 1.843 .571 & 77.318 .872 \\
\hline 2.004 & 1.727.212.208 & 1.108 .378 .620 & 979.405 .947 & 199.366 .286 & 42.334 .205 & 737.705 .456 & 328.338 .959 & 180.686 .620 & 147.481 .100 & 1.917 .598 & 89.381 .984 \\
\hline 2.005 & 2.149 .666 .202 & 1.366 .059 .797 & 1.209 .510 .641 & 226.857 .291 & 55.303 .148 & 927.350 .202 & 383.406 .447 & 257.895 .552 & 166.574 .990 & 2.245 .342 & 130.033 .230 \\
\hline 2.006 & 2.517.121.118 & 1.591 .418 .218 & 1.439.139.394 & 228.280 .791 & 66.714 .577 & 1.144 .144 .026 & 380.559 .615 & 352.633 .707 & 180.969 .820 & 2.528 .532 & 161.290 .050 \\
\hline 2.007 & 2.946 .498 .754 & 1.839 .111 .060 & 1.666 .059 .006 & 268.638 .293 & 75.219 .956 & 1.322 .200 .757 & 441.690 .347 & 426.416 .042 & 206.284 .160 & 2.993 .579 & 203.055 .620 \\
\hline 2.008 & 3.223 .714 .830 & 2.012 .607 .395 & 1.822 .826 .773 & 314.964 .270 & 76.054 .061 & 1.431 .808 .442 & 504.744 .892 & 395.203 .751 & 242.425 .540 & 3.136 .134 & 255.377 .740 \\
\hline 2.009 & 3.238 .236 .477 & 2.014 .006 .136 & 1.812 .466 .946 & 304.978 .971 & 81.805 .479 & 1.425 .682 .496 & 506.518 .161 & 434.134 .138 & 269.798 .180 & 3.313 .822 & 212.005 .230 \\
\hline 2.010 & 3.251 .533 .782 & 2.029 .222 .017 & 1.787 .844 .041 & 269.668 .233 & 79.079 .549 & 1.439 .096 .259 & 511.046 .209 & 432.892 .003 & 282.515 .170 & 3.217 .449 & 234.018 .910 \\
\hline 2.011 & 3.326 .135 .345 & 2.022 .310 .565 & 1.772 .404 .528 & 289.618 .529 & 86.135 .926 & 1.396 .650 .073 & 539.524 .566 & 432.635 .433 & 334.939 .040 & 3.459 .118 & 243.172 .660 \\
\hline
\end{tabular}


Táboa 11: Detalle de partidas do pasivo, separando Interbancario. Datos anuais para o período 2002-2011.

\begin{tabular}{|c|c|c|c|c|c|c|c|c|c|c|c|}
\hline & Total Pasivo & D Interbancario & $\begin{array}{c}\text { Depos (sin } \\
\text { interb.) }\end{array}$ & $\begin{array}{l}\text { Resid. } \\
\text { España }\end{array}$ & RE. AA.PP. & RE. OSR & $\begin{array}{l}\text { Sector } \\
\text { Exterior }\end{array}$ & $\begin{array}{l}\text { Valores } \\
\text { Distintos } \\
\text { Accs. Y } \\
\text { Particips. }\end{array}$ & $\begin{array}{l}\text { Capital y } \\
\text { Reservas }\end{array}$ & $\begin{array}{c}\text { Obra } \\
\text { Benéfico } \\
\text { Social }\end{array}$ & $\begin{array}{l}\text { Otros } \\
\text { Pasivos }\end{array}$ \\
\hline 02 & 1.352 .406 .082 & 171.027 .049 & 909.727.930 & 634.816 .366 & 40.016 .030 & 594.800 .336 & 274.911.564 & 79.516.191 & 114.664 .620 & 1.737 .692 & 75.732 .600 \\
\hline 03 & 1.514 .635 .060 & 3.674.713 & 98.986 .533 & 3.674 .713 & 35.254 .592 & 643.803 .955 & 319.927 .986 & 120.331 .311 & 122.480 .060 & 1.843.571 & 77.318 .872 \\
\hline 004 & 1.727.212.208 & 9.366.286 & 108.378 .620 & 199.366 .286 & 42.334 .205 & 737.705.456 & 328.338 .959 & 6.620 & 147.481 .100 & 1.917.598 & 89.381 .984 \\
\hline 2005 & 2.149.666.202 & 6.857 .291 & 366.059.797 & 226.857.291 & 55.303 .148 & 927.350 .202 & 383.406 .447 & 257.895 .552 & 166.574 .990 & 2.245.342 & 130.033 .230 \\
\hline 2006 & 2.517.121.118 & 228.280.791 & 1.591.418.218 & 228.280 .791 & 66.714 .577 & 1.144 .144 .026 & 380.559 .615 & 352.633.707 & 180.969 .820 & 2.528.532 & 161.290 .050 \\
\hline 2007 & 2.946.498.754 & 268.638.293 & 1.839 .111 .060 & 268.638 .293 & 75.219 .956 & 1.322.200.757 & 441.690 .347 & 426.416 .042 & 206.284.160 & 2.993.579 & 203.055 .620 \\
\hline 2008 & 3.223.714.830 & 314.964.270 & 2.012.607.395 & 314.964 .270 & 76.054 .061 & 1.431 .808 .442 & 504.744 .892 & 395.203.751 & 242.425 .540 & 3.136 .134 & 255.377 .740 \\
\hline 2009 & 3.238.236.477 & 171 & 014.006 .136 & 1.978 .971 & 81.805 .479 & 1.425 .682 .496 & 506.518.161 & 434 & 269.798.180 & .822 & 212.005.230 \\
\hline 2010 & 782 & 233 & 017 & 668.233 & 79.07 & 259 & .209 & & 282.5 & 3 & 234.0 \\
\hline 011 & 3.326.135.345 & 89.618 .529 & 022.310 .565 & 618.529 & 86.135 .926 & 96.650 .073 & 9.524 .566 & 432.635 .433 & 334.939 .040 & 3.459.118 & 243.172.660 \\
\hline
\end{tabular}

Taboa 12: Resumo de Partidas globais do pasivo. Datos anuais para o período 2002-2011. Formato Banco de España.

\begin{tabular}{|c|c|c|c|c|c|c|}
\hline & Total Pasivo & Depósitos & $\begin{array}{l}\text { Valores Distintos } \\
\text { Accs. YParticips. }\end{array}$ & $\begin{array}{l}\text { Capital y } \\
\text { Reservas }\end{array}$ & $\begin{array}{c}\text { Obra } \\
\text { Benéfico } \\
\text { Social }\end{array}$ & $\begin{array}{l}\text { Otros } \\
\text { Pasivos }\end{array}$ \\
\hline 2002 & 1.352 .405 .828 & 1.080 .754 .979 & 79.516 .191 & 114.664 .620 & 1.737 .692 & 75.732 .600 \\
\hline 2003 & 1.514 .634 .884 & 1.192 .661 .246 & 120.331 .311 & 122.480 .060 & 1.843 .571 & 77.318 .872 \\
\hline 2004 & 1.727.212.011 & 1.307 .744 .906 & 180.686 .620 & 147.481 .100 & 1.917 .598 & 89.381 .984 \\
\hline 2005 & 2.149.666.155 & 1.592 .917 .088 & 257.895 .552 & 166.574 .990 & 2.245 .342 & 130.033 .230 \\
\hline 2006 & 2.517.121.128 & 1.819.699.009 & 352.633 .707 & 180.969 .820 & 2.528 .532 & 161.290 .050 \\
\hline 2007 & 2.946 .498 .758 & 2.107 .749 .353 & 426.416 .042 & 206.284 .160 & 2.993 .579 & 203.055 .620 \\
\hline 2008 & 3.223 .715 .704 & 2.327 .571 .665 & 395.203 .751 & 242.425 .540 & 3.136 .134 & 255.377 .740 \\
\hline 2009 & 3.238.236.359 & 2.318.985.107 & 434.134 .138 & 269.798.180 & 3.313 .822 & 212.005 .230 \\
\hline 2010 & 3.251 .534 .538 & 2.298 .890 .250 & 432.892 .003 & 282.515 .170 & 3.217 .449 & 234.018 .910 \\
\hline 2011 & 3.326 .134 .836 & 2.311.929.094 & 432.635 .433 & 334.939 .040 & 3.459 .118 & 243.172 .660 \\
\hline
\end{tabular}

Táboa 13: Datos táboa 12, Formato con Interbancario independente.

\begin{tabular}{|r|r|r|r|r|r|r|r|}
\hline & Total Pasivo & D Interbancario & Depos(sin interb.) & Valores Distintos & Accs. Y Particips. & Capital y Reservas & $\begin{array}{r}\text { Obra Benéfico } \\
\text { Social }\end{array}$ \\
\hline 2002 & 1.352 .406 .082 & 171.027 .049 & 909.727 .930 & 79.516 .191 & 114.664 .620 & 1.737 .692 & 75.732 .600 \\
\hline 2003 & 1.514 .635 .060 & 157.972 .696 & 679.058 .547 & 120.331 .311 & 122.480 .060 & 1.843 .571 & 77.318 .872 \\
\hline 2004 & 1.727 .212 .208 & 168.763 .389 & 780.039 .661 & 180.686 .620 & 147.481 .100 & 1.917 .598 & 89.381 .984 \\
\hline 2005 & 2.149 .666 .202 & 170.467 .474 & 982.653 .350 & 257.895 .552 & 166.574 .990 & 2.245 .342 & 130.033 .230 \\
\hline 2006 & 2.517 .121 .118 & 178.153 .560 & 1.210 .858 .603 & 352.633 .707 & 180.969 .820 & 2.528 .532 & 161.290 .050 \\
\hline 2007 & 2.946 .498 .754 & 174.416 .674 & 1.397 .420 .713 & 426.416 .042 & 206.284 .160 & 2.993 .579 & 203.055 .620 \\
\hline 2008 & 3.223 .714 .830 & 176.351 .204 & 1.507 .862 .503 & 395.203 .751 & 242.425 .540 & 3.136 .134 & 255.377 .740 \\
\hline 2009 & 3.238 .236 .477 & 163.526 .454 & 1.507 .487 .975 & 434.134 .138 & 269.798 .180 & 3.313 .822 & 212.005 .230 \\
\hline 2010 & 3.251 .533 .782 & 176.674 .286 & 1.518 .175 .808 & 432.892 .003 & 282.515 .170 & 3.217 .449 & 234.018 .910 \\
\hline 2011 & 3.326 .135 .345 & 173.536 .888 & 1.482 .785 .999 & 432.635 .433 & 334.939 .040 & 3.459 .118 & 243.172 .660 \\
\hline
\end{tabular}


Táboa 14: Porcentaxes dos compoñentes principais do pasivo. Datos anuais para o período 2002-2011.

\begin{tabular}{|c|c|c|c|c|c|c|}
\hline & $\begin{array}{l}\text { Depósitos (sin } \\
\text { interbancario) }\end{array}$ & $\begin{array}{c}\text { V alores } \\
\text { Distintos } \\
\text { Accs. Y } \\
\text { Particips. }\end{array}$ & $\begin{array}{l}\text { Capitaly } \\
\text { Reservas }\end{array}$ & $\begin{array}{c}\text { Obra } \\
\text { Benéfico } \\
\text { Social }\end{array}$ & $\begin{array}{c}\text { Otros } \\
\text { Pasivos }\end{array}$ & In te rbancario \\
\hline 2002 & $67,27 \%$ & $5,88 \%$ & $8,48 \%$ & $0,13 \%$ & $5,60 \%$ & $12,65 \%$ \\
\hline 2003 & $65,96 \%$ & $7,94 \%$ & $8,09 \%$ & $0,12 \%$ & $5,10 \%$ & $12,79 \%$ \\
\hline 2004 & $64,17 \%$ & $10,46 \%$ & $8,54 \%$ & $0,11 \%$ & $5,17 \%$ & $11,54 \%$ \\
\hline 2005 & $63,55 \%$ & $12,00 \%$ & $7,75 \%$ & $0,10 \%$ & $6,05 \%$ & $10,55 \%$ \\
\hline 2006 & $63,22 \%$ & $14,01 \%$ & $7,19 \%$ & $0,10 \%$ & $6,41 \%$ & $9,07 \%$ \\
\hline 2007 & $62,42 \%$ & $14,47 \%$ & $7,00 \%$ & $0,10 \%$ & $6,89 \%$ & $9,12 \%$ \\
\hline 2008 & $62,43 \%$ & $12,26 \%$ & $7,52 \%$ & $0,10 \%$ & $7,92 \%$ & $9,77 \%$ \\
\hline 2009 & $62,19 \%$ & $13,41 \%$ & $8,33 \%$ & $0,10 \%$ & $6,55 \%$ & $9,42 \%$ \\
\hline 2010 & $62,41 \%$ & $13,31 \%$ & $8,69 \%$ & $0,10 \%$ & $7,20 \%$ & $8,29 \%$ \\
\hline 2011 & $60,80 \%$ & $13,01 \%$ & $10,07 \%$ & $0,10 \%$ & $7,31 \%$ & $8,71 \%$ \\
\hline
\end{tabular}

Táboa 15. Porcentaxes das diferenzas dos valores do pasivo por subperíodos

\begin{tabular}{|c|c|c|c|c|c|c|}
\hline & $\begin{array}{c}\text { D } \\
\text { Interbancario }\end{array}$ & $\begin{array}{l}\text { Depos (sin } \\
\text { interb.) }\end{array}$ & $\begin{array}{l}\text { Valores Distintos } \\
\text { Accs. Y Particips. }\end{array}$ & Capital y Reservas & $\begin{array}{c}\text { Obra Benéfico } \\
\text { Social }\end{array}$ & Otros Pasivos \\
\hline 2008-2002 & $7,7 \%$ & $58,9 \%$ & $16,9 \%$ & $6,8 \%$ & $0,1 \%$ & $9,6 \%$ \\
\hline 2011-2008 & $-24,7 \%$ & $9,5 \%$ & $36,5 \%$ & $90,3 \%$ & $0,3 \%$ & $-11,9 \%$ \\
\hline
\end{tabular}

